\title{
Expression patterns of DEMETER-like DNA demethylases homologs hint at potential involvement in grapevine dormancy release
}

\author{
Valeria De Rosa ${ }^{1 *}$, Rachele Falchi ${ }^{1}$, Alessandro Peressotti ${ }^{1}$ and Giannina Vizzotto ${ }^{1}$ \\ ${ }^{1}$ University of Udine, Department of Food, Environmental, and Animal Sciences, Via delle Scienze 206, 33100 Udine, Italy
}

\begin{abstract}
Climate change represents an undeniable threat to traditional viticulture in many areas of the world. Although an increase of average surface temperatures is expected in the future, late frost occurrences are predicted to be an actual challenge, being budburst the critical stage during which cold hardiness levels dramatically decrease and frost vulnerability is at its maximum. Genomic DNA methylation is known as an important mechanism for gene expression regulation. A sub-group of epigenetic regulators named DEMETER-like DNA demethylases (DMLs) has been shown to be involved in budbreak regulation in Populus trichocarpa. In this study, buds of two Vitis cultivars, Fleurtai (Friulano $\times$ Kozma 20-3) and UD 31-103 (Merlot $\times$ Kozma 20-3), characterized by different levels of resistance to winter freezing temperatures, were sampled during the 2019/2020 winter season. Cold hardiness dynamics were monitored with differential thermal analysis (DTA) at regular intervals. Expression levels of two putative grapevine DEMETER homologs were investigated during natural dormancy conditions. Results show dissimilar deacclimation rates in the two varieties. As observed in other woody species, putative grapevine DEMETERs show downregulation and upregulation trends hinting at a potential involvement in grapevine dormancy release.
\end{abstract}

\section{Introduction}

Climate change represents a multifaceted phenomenon that threatens crop productivity all around the globe [1]. Grapevine phenology is greatly responsive to environmental conditions, with temperature being the most critical factor [2]. Higher temperatures produce an acceleration of grapevine development, with consequent earlier budbreak, flowering and harvest dates. Faster development rates not only impact ripening conditions, which greatly affect berry composition and wine quality, but also compromise the survival of buds and shoots to potential late frosts [3-5].

Green tissues are significantly more vulnerable to freezing damage due to the high hydration levels combined with low supercooling capabilities [6]. Therefore, budburst and leafout have been described as most vulnerable phases in several woody species $[7,8]$. Consequently, sudden occurrences of late freezing temperatures following a period of premature vegetative growth, known as spring frosts, can greatly damage bud tissues thus impairing fruit trees production and causing great economic losses [9,10]. Late frosts are expected to remain a continuing challenge in several areas of the world [11-14]. Moreover, frost damages occurring at budbreak negatively affect grapevine photosynthetic and reproductive tissues alike with consequences that spread on multiple years of development [15].
Bud dormancy in woody perennials is defined as a state of temporary cessation of all visible growth. It can be induced by environmental conditions such as low temperatures and short photoperiod (ecodormancy), or endogenous signals originating from inside (endodormancy) or outside the bud (paradormancy) [16]. Woody perennials need to fulfil a chilling requirement during winter to shift from endodormancy to ecodormancy, when the tissues become responsive to growth-promoting external conditions. Chilling requirements are not thoroughly understood and can currently be predicted only by using empirical models [17]. Cultivated grapevines are generally considered lowchill compared to other fruit trees, however considerable diversity can be found among species and cultivars [18]. Hybrid crosses have been useful in the past to enhance cold resistance to winter freezing temperatures in grapevine; however, wild Vitis species have been observed to be more responsive to mid-winter warm temperatures, leading to earlier budbreak and to a consequent susceptibility to spring frost damage [18].

Gaining a comprehensive understanding of chilling requirement and dormancy release regulation is essential to direct breeding efforts towards the production of delayed-growth cultivars; such an approach could be favourable to lower spring frost damage risk in the face of a changing climate [19].

Epigenetic regulation of processes such as cold stress response, cold acclimation or dormancy regulation has

\footnotetext{
* Corresponding author: derosa.valeria@spes.uniud.it
} 
been an object of interest in plants [20-23], although understanding of it is still limited. Similarly, very little is known about deacclimation, which naturally proceeds into dormancy release, in woody perennials [24].

DNA methylation taking place at the 5' position of cytosines is a renowned conserved epigenetic mechanism involved in both gene expression regulation and genomic stability [25]. DNA demethylation occurs passively during DNA replication, or actively through enzymatic removal of methylated cytosines. In Arabidopsis thaliana, demethylation is carried out by four DEMETER-like DNA demethylases (DMLs) [26], which activate gene expression in response to abiotic or biotic stresses [27,28]. DMLs have also been associated with fruit development in other species such as tomato [29] and grapevine [30], in addition to nodule development in Medicago truncatula [31]. Poplar DML DEMETER-like 10 (PtaDML10) was recently described as a potential chilling-responsive regulator of budbreak. It putatively enables the reactivation of genes controlling meristem activity, and the downregulation of dormancy-related genes [32].

This work aims to ascertain the presence of grapevine DMLs homologs in differently cold tolerant cultivars, and to monitor their expression to understand whether, as observed in poplar, grapevine DMLs could be involved in budbreak regulation.

\section{Materials and methods}

\subsection{Plant material}

Two differently cold tolerant Vitis hybrid cultivars were selected for the study: the white cv. Fleurtai (Friulano $x$ Kozma 20-3), tolerant to freezing temperatures up to $23^{\circ} \mathrm{C}$, and the red cv. UD 31-103 (Merlot $\times$ Kozma 20-3), tolerant to freezing temperatures up to $-20^{\circ} \mathrm{C}$. Plants were located at the Experimental Farm "A. Servadei" (University of Udine, Northern Italy) and grown in the field. During the 2019/2020 winter season, buds were collected at 15 days' intervals and immediately used for cold hardiness determination, or stored at $-80^{\circ} \mathrm{C}$ for subsequent gene expression analysis.

\subsection{Cold hardiness monitoring}

For each sampling time, 3 biological replicates of 5 buds each were used for cold hardiness determination with differential thermal analysis (DTA) using thermoelectric modules (TEM) and temperature probes placed in a T700BXPRO temperature-controlled freezing chamber (FDM, Rome, Italy). Temperature was quickly lowered to $7^{\circ} \mathrm{C}$ for 1 hour and subsequently lowered to $-25^{\circ} \mathrm{C}$ at a rate of $-2.5^{\circ} \mathrm{C} \cdot \mathrm{h}^{-1}$. A CR1000 data-logger (Campbell Scientific, Logan, UT, USA) was used for data recording. Temperature and voltage signals were analysed using RStudio software (https://www.r-project.org/).

\subsection{Gene expression analysis}

Grapevine DMLs homologs were BLAST-searched in the grapevine whole genome using poplar PtDML10 sequence (Phytozome accession: Potri.010G234400.1) and A. thaliana DML1 (AT2G36490). Three sequences were found and putatively named VVDEMETER1 (VvDEM1, GSVIVT01034713001), VvDEMETER2 (VvDEM2, GSVIVT01031400001) and VvDEMETER3 ( $V v D E M 3$, GSVIVT01033777001). Primers to detect $V v D E M$ expression were built with Primer-BLAST tool on NCBI (Table 1).

For each sampling time, RNA extraction was performed from 3 biological replicates of 10 buds using the Spectrum ${ }^{\mathrm{TM}}$ Plant Total RNA kit (Sigma-Aldrich, St. Louis, MO, USA). cDNA was synthesized with QuantiTect ${ }^{\mathbb{R}}$ Reverse Transcription kit (Qiagen, Hilden, Germany), and real-time PCR was carried out with SsoFast ${ }^{\mathrm{TM}}$ EvaGreen ${ }^{\circledR}$ Supermix (Bio-Rad, Hercules, CA, USA) as described in Sivilotti et al., 2017 [33] by primers listed in Table 1.

Statistical analyses were performed using SigmaPlot 12.0 (https://systatsoftware.com/).

Table 1. List of primers used for $V v D E M$ cDNA amplification.

\begin{tabular}{|c|c|c|c|}
\hline Gene & & Sequences (5'-3') & $\begin{array}{c}\text { Expected } \\
\text { product size }\end{array}$ \\
\hline VvDEMI & $\mathbf{F}$ & $\begin{array}{l}\text { AATGAGGGGAGAGTGCAGAC } \\
\text { TATGCATTGCGGTTCTGGTG }\end{array}$ & $247 \mathrm{bp}$ \\
\hline VvDEM2 & $\mathbf{F}$ & $\begin{array}{l}\text { CACATCTCCTCGACCCAAGT } \\
\text { GTGTAGGGATGGAAGTGGCT }\end{array}$ & 197 bp \\
\hline VvDEM3 & $\mathbf{R}$ & $\begin{array}{l}\text { CGCACTGTGTACTTTGGGAC } \\
\text { GTCAACCTGCTTGCTGGAAA }\end{array}$ & $170 \mathrm{bp}$ \\
\hline
\end{tabular}

\section{Results}

\subsection{Cold hardiness determination}

DTA analysis was successful in determining cold hardiness levels of Fleurtai and UD 31-103 buds throughout the 2019/2020 winter season. Low temperature exotherms (LTEs), which represent temperatures corresponding to lethal freezing events of intracellular water, are shown in Figure 1. Cold acclimation appeared to have already started in buds of both cultivars by the first half of December and sharply reached its maximum level by the second half of December, with a deviation of about $10^{\circ} \mathrm{C}$, consistently with the lowest temperatures registered in the area (Figure 2 ). Deacclimation also started concomitantly in the two cultivars during the first part of January, but appeared to proceed with possibly different rhythms in buds of cv. UD 31-103 compared to cv. Fleurtai. In fact, in March the two varieties reached the greatest divergence, with cv. Fleurtai seemingly proceeding towards deacclimation, as suggested by the recording of cold hardiness levels comparable to those observed in November, while cv. UD 
31-103 LTEs remained stable. Detailed LTEs values are listed in Table 2.

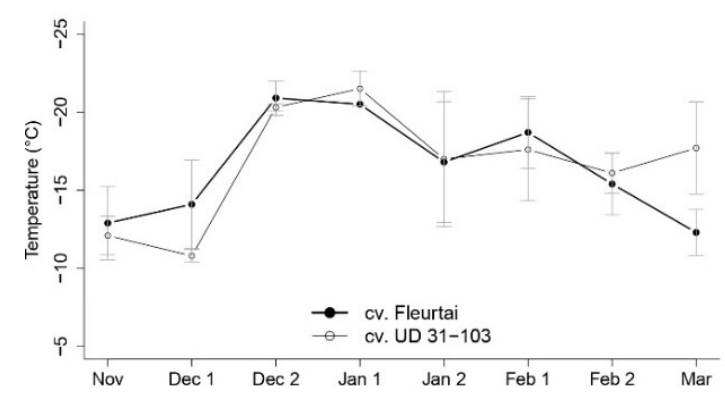

Figure 1. Low-temperature exotherms (LTEs) of grapevine buds during the 2019/2020 winter season. Results are expressed as mean of 3 biological replicates \pm standard deviation.

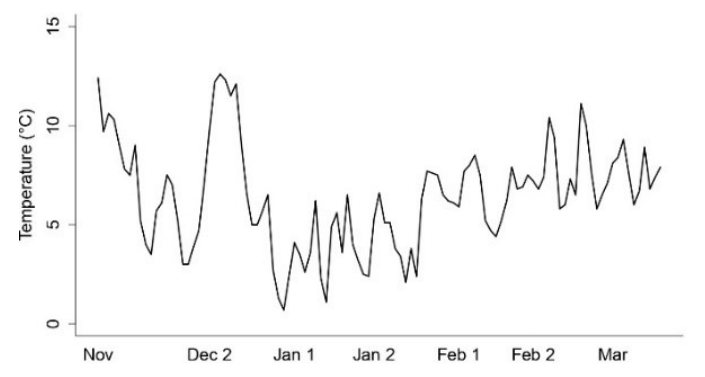

Figure 2. Average daily temperatures during the 2019/2020 winter season. Data recorded by the S. Osvaldo (Udine, Italy) weather station managed by ARPA FVG.

Table 2. List of measured LTEs in buds of cvs. Fleurtai and UD 31-103.

\begin{tabular}{l|cl}
\hline Sampling date & cv. Fleurtai & cv. UD 31-103 \\
\hline Nov & $-12,9^{\circ} \mathrm{C}$ & $-12,1{ }^{\circ} \mathrm{C}$ \\
Dec 1 & $-14,1^{\circ} \mathrm{C}$ & $-10,8^{\circ} \mathrm{C}$ \\
Dec 2 & $-20,9{ }^{\circ} \mathrm{C}$ & $-20,3{ }^{\circ} \mathrm{C}$ \\
Jan 1 & $-20,5{ }^{\circ} \mathrm{C}$ & $-21,5^{\circ} \mathrm{C}$ \\
Jan 2 & $-16,8^{\circ} \mathrm{C}$ & $-17,0^{\circ} \mathrm{C}$ \\
Feb 1 & $-18,7{ }^{\circ} \mathrm{C}$ & $-17,6{ }^{\circ} \mathrm{C}$ \\
Feb 2 & $-15,4{ }^{\circ} \mathrm{C}$ & $-16,1^{\circ} \mathrm{C}$ \\
Mar & $-12,3{ }^{\circ} \mathrm{C}$ & $-17,7{ }^{\circ} \mathrm{C}$ \\
\hline
\end{tabular}

\subsection{Grapevine DEMETER expression}

DMLs expression were tested in both grapevine cvs. Fleurtai and UD 31-103 plants. No expression of VvDEM2 was detected in bud tissue, thus excluding it from further analysis. Expression levels of $V v D E M 1$ and $V v D E M 3$ are shown in Figure $3 \mathrm{~A}$ and $3 \mathrm{~B}$, exhibiting similar trends in the considered varieties. In detail, VvDEM1 expression remained stable throughout the season in both cultivars with the exception of a statistically significant upregulation in October in cv. UD 31-103 (Figure 3A). VvDEM3 expression underwent significant variations in both cultivars. In particular, a significant downregulation was detected during the coldest winter months, consistent with the highest registered levels of freezing tolerance (Figure 1). A statistically significant upregulation of $V v D E M 3$ took place during the deacclimation process in cv. UD 31-103. A tendential uregulation is also observable in cv. Fleurtai in the same phase (Figure 3B).
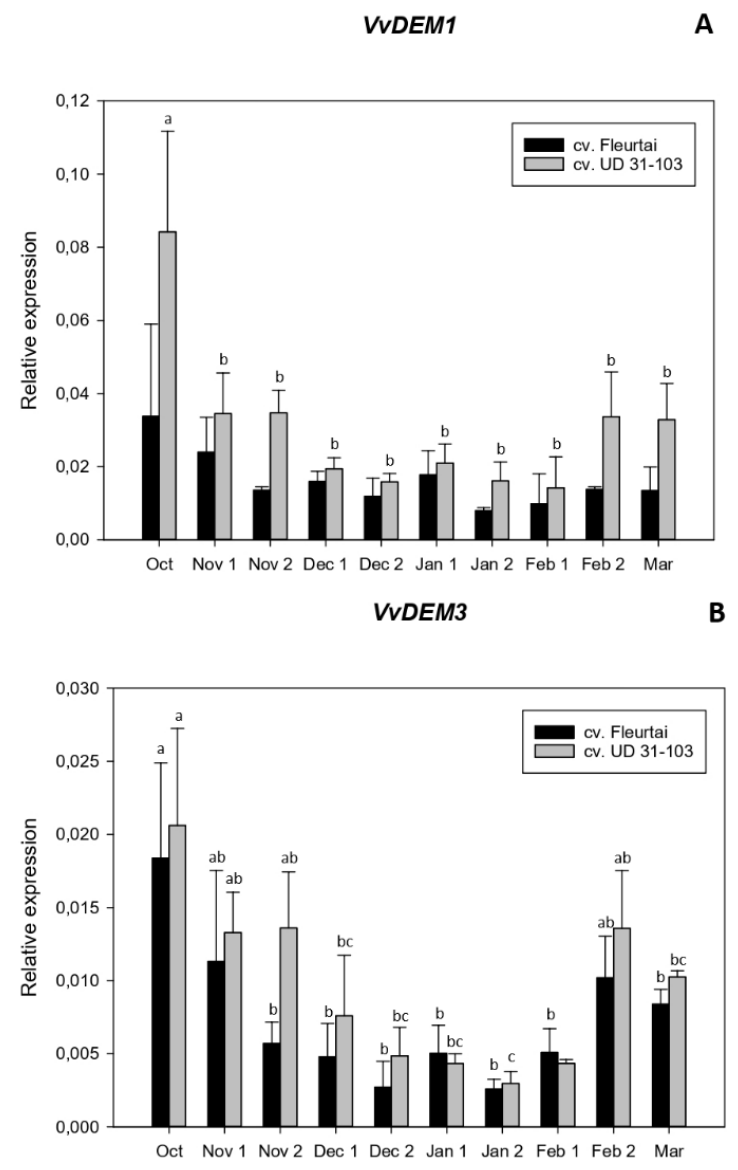

Figure 3. Expression patterns of $V v D E M 1$ and $V v D E M 3$ in buds of field-grown cvs. Fleurtai and UD 31-103 grapevine plants. Results are expressed as mean of 3 biological replicates \pm standard deviation. Statistical analyses were performed within each variety using one-way ANOVA and Tukey HSD as post hoc test for all pairwise multiple comparison procedures.

\section{Discussion}

Cold acclimation and deacclimation are driven by both genetic factors and environmental conditions [34]. In this context, species within the Vitis genus represent a valuable source of variability with a wide range of chilling requirements and budburst rates [18]. Paradoxically, grapevine hybrids most resistant to freezing temperatures have also been observed to be the most vulnerable to spring frost damage due to higher responsiveness to warm temperatures [35]. DTA carried out on Fleurtai and UD 31-103 buds confirms this, since cv. Fleurtai, characterized by a greater winter freezing tolerance compared to $\mathrm{cv}$. UD $31-103$, is also the fastest to deacclimate. $V v D E M 3$ expression patterns suggest a role in dormancy release comparable to the observations carried out in P. trichocarpa [32]. 
Taken together our results allow hypothesizing that a DEMETER-dependent DNA demethylation could be involved, also in a tree crop such as grapevine, in the regulation of dormancy-growth cycle. Further experiments, including methylome and functional studies, involving early-budbreak and late-budbreak varieties, are needed to confirm and further reinforce $V v D E M$ s putative role as transcriptional regulators in the context of grapevine dormancy release.

If confirmed, these preliminary results may have important implications for both research and breeding programs.

VDR activity was supported by a grant of the Italian Ministry of Education, Research and University (MIUR).

\section{References}

1. Climate Change 2014: Synthesis Report. Contribution of Working Groups I, II and III to the Fifth Assessment Report of the Intergovernmental Panel on Climate Change [Core Writing Team R.K. Pachauri and L.A. Meyer (eds.)]. IPCC, Geneva, Switzerland, 151 pp. (2014)

2. C. van Leeuwen, P. Darriet, J. Wine Econ. 11, 150167 (2016)

3. W.M. Kliewer, R.E. Torres, Am. J. Enol. Vitic. 23, 71-77 (1972)

4. B. G. Coombe, Acta Hortic, 23-36 (1987)

5. M. Bonada, D. W. Jeffery, P. R. Petrie, M. A. Moran, V. O. Sadras, Aust. J. Grape Wine Res. 21, 240-253 (2015)

6. A. Fennell, J. Crop Improv. 10, 201-235 (2004)

7. Y. Vitasse, A. Lenz, C. Körner, Front. Plant Sci. 5, 541 (2014)

8. A. Lenz, G. Hoch, C. Körner, Y. Vitasse, Funct. Ecol. 30, 1480-1490 (2016)

9. T. R. Ault, G. M. Henebry, K. M. de Beurs, M. D. Schwartz, J. L. Betancourt, D. Moore, Eos, Trans. Am. Geophys. Union 94, 181-182 (2013)

10. L. Gu, P. J. Hanson, W. Mac Post, D. P. Kaiser, B. Yang, R. Nemani, S. G. Pallardy, and T. Meyers, Bioscience 58, 253-262 (2008)

11. Q. Ma, J.G. Huang, H. Hänninen, F. Berninger, Glob. Chang. Biol. 25, 351-360 (2019)

12. C.K. Augspurger, Ecology 94, 41-50 (2013)

13. G. Sgubin, D. Swingedouw, G. Dayon, I. García de Cortázar-Atauri, N. Ollat, C. Pagé, C. van Leeuwen, Agric. For. Meteorol. 250-251, 226-242 (2018)

14. Y. Vitasse and M. Rebetez, Clim. Change 149, 233 (2018)

15. M.J. Carmona, J. Chaïb, J.M. Martínez-Zapater, M.R. Thomas, J. Exp. Bot. 59, 2579-2596 (2008)

16. G.A. Lang, J.D. Early, G.C. Martin, R.L. Darnell, Hortic. Sci. 22, 371-377 (1987)

17. E. Luedeling, Sci. Hortic. (Amsterdam). 144, 218229 (2012)
18. J.P. Londo, L.M. Johnson, Environ. Exp. Bot. 106, 138-147 (2014)

19. V. De Rosa, G. Vizzotto, R. Falchi, Front. Plant Sci. 12, 644528 (2021)

20. G. Ríos, C. Leida, A. Conejero, M.L. Badenes, Front. Plant Sci. 5, 247 (2014)

21. T. Liu, Y. Li, W. Duan, F. Huang, X. Hou, J. Exp. Bot. 68, 1213-1224 (2017)

22. J. Park, C.J. Lim, M. Shen, H.J. Park, J.Y. Cha, E. Iniesto, V. Rubio, T. Mengiste, J.K. Zhu, R. A. Bressan, S.Y. Lee, B. ha Lee, J.B. Jin, J.M. Pardo, W.Y. Kim, D.J. Yun, Proc. Natl. Acad. Sci. U. S. A. 115, E5400-E5409 (2018)

23. K. Rothkegel, P. Sandoval, E. Soto, L. Ulloa, A. Riveros, V. Lillo-Carmona, J. Cáceres-Molina, A. M. Almeida, C. Meneses, Front. Plant Sci. 11, 1115 (2020)

24. K. Vyse, M. Pagter, E. Zuther, D. K. Hincha, J. Exp. Bot. 70, 4595-4604 (2019)

25. H. Zhang, Z. Lang, J.K. Zhu, Nat. Rev. Mol. Cell Biol. 19, 489-506 (2018)

26. J. K. Zhu, Annu. Rev. Genet. 43, 143-166 (2009)

27. A. Yu, G. Lepère, F. Jay, J. Wang, L. Bapaume, Y. Wang, A. L. Abraham, J. Penterman, R. L. Fischer, O. Voinnet, and L. Navarro, Proc. Natl. Acad. Sci. U. S. A. 110, 2389-2394 (2013)

28. T. N. Le, U. Schumann, N. A. Smith, S. Tiwari, P. C. Khang Au, Q. H. Zhu, J. M. Taylor, K. Kazan, D. J. Llewellyn, R. Zhang, E. S. Dennis, and M. B. Wang, Genome Biol. 15, 458 (2014)

29. R. Liu, A. How-Kit, L. Stammitti, E. Teyssier, D. Rolin, A. Mortain-Bertrand, S. Halle, M. Liu, J. Kong, C. Wu, C. Degraeve-Guibault, N. H. Chapman, M. Maucourt, T. C. Hodgman, J. Tost, M. Bouzayen, Y. Hong, G. B. Seymour, J. J. Giovannoni, P. Gallusci, Proc. Natl. Acad. Sci. U. S. A. 112, 10804 (2015)

30. L. Shangguan, X. Fang, H. Jia, M. Chen, K. Zhang, J. Fang, Physiol. Mol. Biol. Plants 26, 617-637 (2020)

31. C. Satgé, S. Moreau, E. Sallet, G. Lefort, M. C. Auriac, C. Remblière, L. Cottret, K. Gallardo, C. Noirot, M. F. Jardinaud, P. Gamas, Nat. Plants 2, 16166 (2016)

32. D. Conde, A. L. Le Gac, M. Perales, C. Dervinis, M. Kirst, S. Maury, P. González-Melendi, I. Allona, Plant Cell Environ. 40, 2236-2249 (2017)

33. P. Sivilotti, R. Falchi, J.C. Herrera, B. Škvar, L. Butinar, M. Sternad Lemut, M. Bubola, P. Sabbatini K. Lisjak, A. Vanzo, J. Agric. Food Chem. 65, 84268434 (2017)

34. M. Wisniewski, A. Nassuth, R. Arora, Front. Plant Sci. 9, 1394 (2018)

35. J. C. Ferguson, M. M. Moyer, L. J. Mills, G. Hoogenboom, M. Keller, Am. J. Enol. Vitic. 65, 59$71(2014)$ 